\title{
Warning of retaliation over access to physics facilities
}

London. European countries that restrict the access of researchers from Japan and the United States to nuclear physics facilities built with European funds risk retaliation against their own scientists, according to the report of a group of advisers to the Organization for Economic Cooperation and Development (OECD).

The warning has been triggered by a recent decision by the Institut Laue-Langevin (ILL) in Grenoble, France, to restrict access to scientific groups from member states, or groups collaborating with them. The decision was made by the ILL's steering committee in the light of tight budgetary constraints and increasing demand for access to its beam lines.

The warning of retaliation also coincides with a meeting next week of representatives from OECD member states at the Oak Ridge National Laboratory (ORNL) in Tennessee. The meeting will pursue recommendations on future neutron sources made at an expert meeting on synchrontron radiation sources and neutron beams organized by the OECD's Megascience Forum in Risø, Denmark, late last year.

Topics to be addressed at next week's meeting, at which the report of the Risø meeting will be published, include closer collaboration on the planning and design of advanced neutron facilities, instrumentation for existing beamlines and access to current and future neutron sources.

Two main machines are under consideration. The United States is drawing up plans for a powerful research reactor, the \$2.7-billion Advanced Neutron Source (ANS), at ORNL. At the same time, Europe is considering building a spallation (pulsed) neutron source, to be known as the European Spallation Source, whose location is still under discussion.

Many physicists feel that, given the costs of the two facilities - as well as the possible precedent set by ILL's recent decision some agreement on how they might be 'shared' by scientists on both sides of the Atlantic needs to be negotiated in advance.

In addition to the ILL, the newly opened European Synchrotron Radiation Facility (ESRF) at Grenoble, also operates under rules that break with the traditional practice of providing open access to international facilities based purely on the scientific merit of research proposals.

The new rules at both ILL and ESRF are more restrictive than those for large facilities in Japan and the United States, sparking fears that these countries might retaliate. John Axe, for example, scientific programme director of the High Flux Beam Reactor (HFBR) at the Brookhaven National Labo- ratory (BNL) in Long Island, New York, compares the situation to the imposition of import taxes by one country on goods made elsewhere.

Retaliation can soon escalate, says Axe, with countries being denied access to potential markets for their products. "We understand the financial pressures that have driven that decision [at ILL], but we are sorry to see it. I'm hoping that other facilities won't follow their lead and that ILL will eventually reconsider their position."

According to Peter Tindemans, chairman of the OECD Megascience Forum and director of research and science policy at the ministry of education, culture and science in the Netherlands, one of the major aims of the Oak Ridge meeting is to identify "ways out of this tension" between governments demanding a fair return on their investment, and others who want open access for all.

Bill Appleton of ORNL, associate director for the ANS, says that the issues of collaboration, coordination of instrumentation and access to facilities have to be resolved. "Given the way the costs of major facilities are going in this country, there won't be a spallation source built in the United States, so we'll need to share facilities", he says.

The International Union of Pure and Applied Physics (IUPAP) is also keen to promote close coordination through open access to facilities. Axe plans to present a statement to the Oak Ridge meeting on behalf of the US liaison committee of IUPAP, emphasizing the importance of this issue. It has been drafted in conjunction with US high-energy physicist, some of whom are concerned about possible restrictions on their access to the proposed Large Hadron Collider at the European Laboratory for Particle Physics (CERN) in Geneva. Maggie Verrall

\section{Brussels suggests 'variable geometry' research projects}

London. The European Commission (EC) in Brussels last week suggested to the 12 member states of the European Union (EU) that joint research programmes involving some - but not all — members should for the first time be included within the commission's five-year 'framework' programmes of collaborative research.

At the same time, the commission suggested that, in order to avoid individual member states from feeling left out of arrangements that are referred to in France as 'variable geometry', a balanced portfolio of multilateral programmes should be approved simultaneously by the commission.

Both suggestions were made by the commissioner for research, Antonio Ruberti. They are among a number of new developments being proposed by Ruberti and his staff to fulfil a mandate in the Maastricht Treaty to improve the co-ordination of research policies between member states.

Some member states themselves are wary of the implications of these moves, concerned that they could lead to an excessive concentration of power in the hands of the commission, and could also encourage a 'two-speed' Europe in research. Participants at a meeting of the commission's own science policy advisory committee (CREST) are said to have given the proposals a-cool response at a meeting last Friday.

But the commission itself feels that the Maastricht Treaty has given it the green light to introduce measures designed to ensure an increasing convergence between the research policies of EU member states.

Areas in which Brussels officials feel that the potential for convergence exists include employment practices, policies on funding for large facilities, and the use of forecasting techniques in identifying research priorities.

\section{Cresson tipped for EU research post}

\begin{abstract}
Paris. Edith Cresson (right), the former French socialist prime minister, is being tipped to succeed Antonio Ruberti as the European Union (EU)'s research commissioner when he steps down at the end of the year.
\end{abstract}

According to uncon-

firmed reports, Cresson

and Jacques Santer, the new president of the commission, agreed on her nomination at a meeting in Paris last week. Cresson is said to have preferred the post of relations with Eastern Europe,

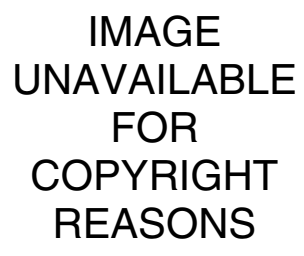

but to have lacked the necessary political support from Edouard Balladur, the French prime minister.

During her spell as prime minister, Cresson was a strong advocate of industrial policy. Her appointment could therefore lead to closer relations between the directorates for science (DGXII) and industry (DGIII), as well as a shift in EU research funding towards more focused social and industrial goals.
D. B. 